\title{
Role of the Nitric Oxide-cGMP System in the Regulation of Ductus Arteriosus Patency in Fetal Rats
}

\author{
Tatsuya TAKIZAWA, Emiko HORIKOSHI and Akira KAMATA \\ Department of Developmental and Reproductive Biotechnology, Azabu University School of Veterinary Medicine, Fuchinobe, \\ Sagamihara-shi, Kanagawa 229-8501, Japan
}

(Received 11 June 1999/Accepted 6 August 1999)

ABSTRACT. The purpose of this study was to examine the role of the nitric oxide (NO) and cyclic guanosine monophosphate (cGMP) system in the regulation of the ductus arteriosus (DA) patency in fetal rats. Pregnant rats were administered $\mathrm{N}^{\mathrm{G}}$-nitro-L-arginine methyl ester (L-NAME, $50 \mathrm{mg} / \mathrm{kg}$, ip), an NO synthase (NOS) inhibitor; methylene blue (30,50 and $100 \mathrm{mg} / \mathrm{kg}$, ip), a soluble guanylate cyclase inhibitor; or indomethacin $(3 \mathrm{mg} / \mathrm{kg}$, po), a cyclooxygenase inhibitor, at various times before cesarean section. Dams were decapitated to obtain the fetuses by cesarean section, and fetuses were rapidly frozen in an acetone-dry ice mixture. Using rapid freezing and shaving methods, the calibers of the DA, pulmonary artery (PA) and descending aorta (Ao) were measured to evaluate the effects of treatment. LNAME reduced the DA calibers to $86 \%$ of the initial values, but recovery to the control levels occurred $6 \mathrm{hr}$ after the injection. Indomethacin decreased the DA calibers to $34 \%$ of the control values and sustained the DA constriction until $24 \mathrm{hr}$ after the treatment. Methylene blue caused DA constriction to almost the same degree as indomethacin, but the levels normalized within $24 \mathrm{hr}$ after the treatment. We conclude that L-NAME caused a slight constriction of the DA, whereas methylene blue and indomethacin caused marked constriction of the vessels, suggesting that the NO-cGMP system as well as prostaglandins contribute to the DA patency.—KEY wORDS: ductus arteriosus, indomethacin, methylene blue, $\mathrm{N}^{\mathrm{G}}$-nitro-L-arginine methyl ester, nitric oxide.

J. Vet. Med. Sci. 61(12): 1277-1280, 1999

The ductus arteriosus (DA) connects the main pulmonary artery (PA) and the descending aorta (Ao) during the fetal period, allowing the blood flow from the right ventricle to bypass the lungs. Previous studies have demonstrated that dilator prostaglandins, especially $\mathrm{PGE}_{2}$, play a major role in maintaining DA patency in utero [4-6, 12]. Endothelialderived relaxing factor-nitric oxide (EDRF-NO) has emerged as a major determinant of vascular tone under both physiologic and pathophysiologic conditions [15]. Recent studies indicated that NO contributes to the patency of the DA in vitro, but to a degree less than that of dilator prostaglandins, suggesting that $\mathrm{NO}$ is an accessory to $\mathrm{PGE}_{2}$ in the regulation of ductal patency [7]. NO as well as carbon monoxide (CO) elevated intracellular cyclic guanosine monophosphate (cGMP) concentrations through the stimulation of guanylate cyclase, and caused smooth muscle relaxation [16, 17]. However, the relative contribution of the NO-cGMP system to the regulation of the DA caliber has not been studied in vivo.

The present study was designed to obtain information about the role of the NO-cGMP system in the regulation of the DA caliber in the fetal rat. We investigated the effects of $\mathrm{N}^{\mathrm{G}}$-nitro-L-arginine methyl ester (L-NAME), a NO synthase (NOS) inhibitor and methylene blue, a soluble guanylate cyclase inhibitor, on the caliber of the great vessels. We also examined the effects of indomethacin, a cyclooxygenase inhibitor, to compare the effects of prostaglandins on these vessels with those of the NO-cGMP system.

\section{MATERIALS AND METHODS}

Female Crj: Wistar rats, 10-12 weeks old at the time of mating, were used. They were maintained on a commercial diet (CE-2, Clea Japan, Tokyo) and tap water ad libitum, and kept in a room at temperature of $22 \pm 3^{\circ} \mathrm{C}$ with relative humidity of $55 \pm 10 \%$. Three females were placed with a male overnight and examined the next morning for the presence of sperm in the vaginal smear. The day on which sperm was found was designated as day 0 of gestation, and the females were caged individually thereafter.

Effects of L-NAME, methylene blue or indomethacin on mature fetuses: The effects of L-NAME, methylene blue or indomethacin on the calibers of fetal DA, PA and Ao were examined in 21-day-old fetuses. L-NAME (Biomol, Plymouth Meeting, U.S.A.) or methylene blue (Sigma Chemical, St. Louis, U.S.A.) was dissolved in sterile saline, and injected intraperitoneally into each pregnant rat at a dose of $50 \mathrm{mg} / \mathrm{kg}$ or $100 \mathrm{mg} / \mathrm{kg}$, respectively, doses sufficient to elevate the mean arterial pressure [9, 18]. Indomethacin (Wako Pure Chemical, Osaka, Japan) was dissolved in $\mathrm{Na}_{2} \mathrm{CO}_{3}$ solution $(5.7 \mathrm{mg} / \mathrm{ml})$, and then diluted with sterile saline and administered orally via a gastric tube to each pregnant rat at $3 \mathrm{mg} / \mathrm{kg}$, a dose sufficient to cause severe ductal constriction [2,14]. The administration of these agents was performed at various times before decapitation. The pregnant rats were killed by decapitation at 1 p.m. on day 21 of gestation. Fetuses were delivered by cesarean section and rapidly immersed in an acetone-dry ice mixture. The frozen fetuses were weighed individually, and then 3-7 fetuses of similar weight were selected from 
each litter and stored for several days at $-20^{\circ} \mathrm{C}$ until the calibers of the DA, PA and Ao were measured. These measurements were obtained by whole-body freezing and shaving methods described elsewhere [2,3]. A total of 1422 fetuses from 3-5 litters were used at each point.

The dose-dependent effect of methylene blue was examined. Methylene blue was injected intraperitoneally to pregnant rats at three dosage levels $(30,50,100 \mathrm{mg} / \mathrm{kg}) 3$ $\mathrm{hr}$ before cesarean section on day 21 of gestation. Frozen fetuses were obtained as described above, and the calibers of the fetal DA, PA and Ao were determined as described above. A total of 21-42 fetuses from 3-6 litters were used at each point.

Data analysis: Results are expressed as the mean \pm S.E.M. The statistical analysis of data was performed with Student's $t$ test in the first experiment. The differences among groups in the second experiment were assessed using analysis of variance (ANOVA). If a difference among the groups was demonstrated, Scheffe's test was applied to assess the difference between groups. A $p$ value less than 0.05 was considered statistically significant.

\section{RESULTS}

L-NAME caused a slight but significant decrease in the DA caliber of the fetal rats from 1 to $4.5 \mathrm{hr}$ after maternal injection $(p<0.01$, Fig. 1A), with recovery to the control value within $6 \mathrm{hr}$ of the injection. The most remarkable decrease in the DA caliber was observed at $3 \mathrm{hr}$ after the injection ( $86 \%$ of control, $p<0.01$, Fig. 1A). However, LNAME did not affect the calibers of the PA and Ao, except for a slight, transient increase in the Ao at $1 \mathrm{hr}$ after injection.

Methylene blue caused a significant decrease in the DA caliber of the fetal rats from 3 to $12 \mathrm{hr}$ after the injection $(p<0.01$, Fig. 1B), and caused a slight increase in the DA caliber at $24 \mathrm{hr}$ after the injection. Methylene blue also caused a slight but significant decrease in the calibers of the $\mathrm{PA}$ and Ao at $3 \mathrm{hr}$ after the injection: recovery occurred within $6 \mathrm{hr}$ of the injection, and there was a slight increase in the PA caliber at $24 \mathrm{hr}$ after the injection. The most remarkable constriction of the DA was observed at $3 \mathrm{hr}$ after the injection ( $37 \%$ of control, $p<0.01$, Fig. 1B), and the Ao and PA also decreased in caliber at this time. Dosedependent effects of methylene blue on the calibers of the great vessels were examined at $3 \mathrm{hr}$ after injection. The constrictive effects of methylene blue on DA, PA and Ao were dose-dependent (Fig. 2); however, the constrictive effects of methylene blue on the PA and Ao were much smaller than that on the DA.

Indomethacin decreased the ductal caliber significantly at $1 \mathrm{hr}$ after maternal treatment and sustained DA constriction until $24 \mathrm{hr}$ after administration ( $p<0.01$, Fig. 1C). The most remarkable decrease in the DA caliber was observed at $3 \mathrm{hr}$ after the treatment ( $34 \%$ of control, $p<0.01$, Fig. 1C). Indomethacin caused a slight increase in the caliber of the Ao from 3 to $24 \mathrm{hr}$ after maternal
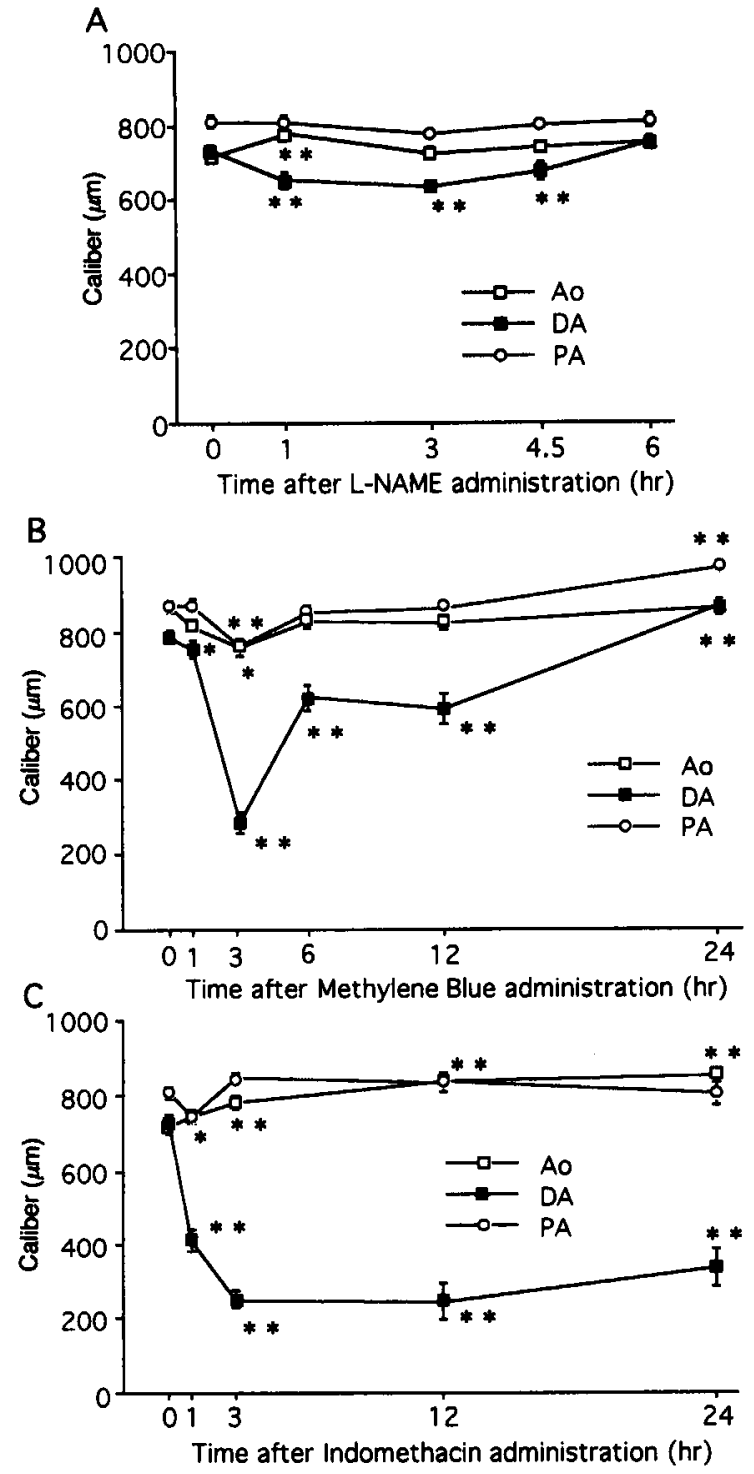

Fig. 1. Changes in the calibers of the DA, PA and Ao of fetal rats after maternal treatment with L-NAME (A, $50 \mathrm{mg} / \mathrm{kg}$ ), methylene blue $(\mathrm{B}, 100 \mathrm{mg} / \mathrm{kg})$ and indomethacin $(\mathrm{C}, 3 \mathrm{mg} / \mathrm{kg})$ on day 21 of gestation. The values with vertical bars represent the mean caliber and S.E.M. of 14-22 fetuses from 3-5 litters. $*$, **: Significantly different from the initial value for each vessel $(*: p<0.05, * *: p<0.01)$. Closed squares: ductus arteriosus (DA), open circles: pulmonary artery (PA), open squares: descending aorta (Ao).

administration and a slight decrease in the PA caliber at 1 hr after maternal treatment.

\section{DISCUSSION}

Although, NO is an important modulator of pulmonary and systemic vascular resistance in the normal fetus and transitional circulation [1], its potential role in the regulation 


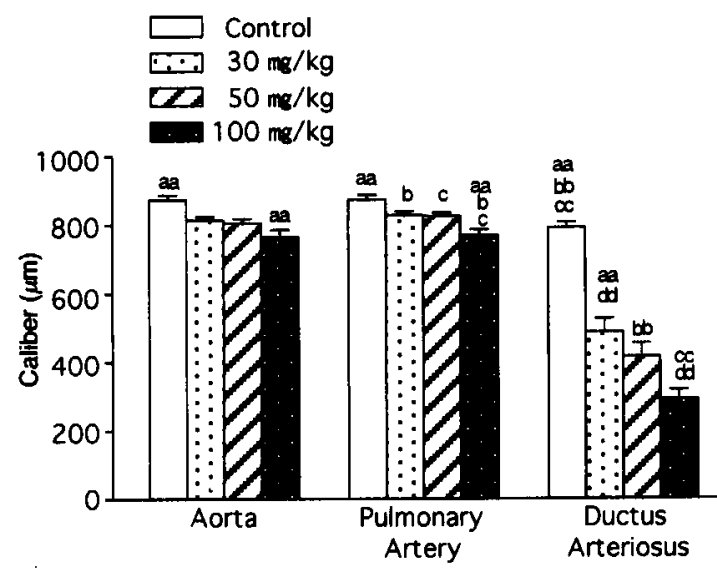

Fig. 2. Dose-dependent effect on the constriction of the DA, PA and Ao of fetal rats $3 \mathrm{hr}$ after maternal treatment with methylene blue on day 21 of gestation. Open columns represent controls, dotted columns represent the $30 \mathrm{mg} / \mathrm{kg}$ group, hatched and shaded columns represent the $50 \mathrm{mg} / \mathrm{kg}$ and $100 \mathrm{mg} / \mathrm{kg}$ group, respectively. The columns with vertical bars represent the mean caliber and S.E.M. of 21-42 fetuses from 3-6 litters. Significant difference between groups showing the same characters (ex., a: $p<0.05$, aa: $p<0.01$ ).

of the DA caliber has not been studied in detail in vivo. Coceani and colleagues [7] reported that isolated DA from fetal lambs contracted in the presence of a NOS inhibitor in vitro, but to a degree less than that which occurred in the presence of a prostaglandin synthesis inhibitor, suggesting that $\mathrm{NO}$ plays a role supplemental to $\mathrm{PGE}_{2}$ in DA patency. Using hemodynamic measurements, Fox and co-workers [9] reported that $\mathrm{N}^{\mathrm{G}}$-nitro-L-arginine at a dose sufficient to increase mean arterial pressure had a much smaller contractile effect than indomethacin on the fetal lamb ductus in vivo.

We report here similar findings concerning DA constriction, in that L-NAME maximally decreased the DA caliber to $86 \%$ of the initial control value after the injection, whereas indomethacin maximally decreased the DA caliber to $34 \%$ of the initial control value. In addition, we report that methylene blue, a soluble guanylate cyclase inhibitor, maximally decreased the DA caliber to $37 \%$ of the initial value. The maximal constrictive effect of methylene blue on the DA was thus comparable to that of indomethacin, whereas the maximal effect of L-NAME on the DA was marked weaker than that of methylene blue and of indomethacin. Although we did not examine the effects of various doses of each agent in the present study, the constrictive effect of lower doses of methylene blue on the DA caliber was greater than that of L-NAME.

Smooth muscle contains a CO-forming enzyme, hemeoxygenase $\mathrm{HO}$ ), which can produce $\mathrm{CO}$ from heme, and locally produced $\mathrm{CO}$ may cause vasodilatation through the formation of cGMP [16]. Recently, Coceani et al. [8] reported that $\mathrm{CO}$ potently relaxed the ductus arteriosus in the lamb, and that the inducible isoform of $\mathrm{HO}$ was localized to endothelial as well as smooth muscle cells in the ductal tissue. Based on these findings, we speculate that the difference in the effect of L-NAME and methylene blue is due to the $\mathrm{CO}$ action produced in the DA, and that locally produced CO may play a major role in DA patency in mature rat fetus, although it remains to be established whether $\mathrm{CO}$ acts as a dilator of the DA under physiological conditions in utero [19]. Other possible reasons for the differences of the effects of methylene blue and L-NAME include the possibility that methylene blue may have pharmacological effects other than soluble guanylate cyclase inhibition, such as inhibition of NOS [13], and nonselective effects due to the generation of oxygen radicals $[11,21]$.

L-NAME and indomethacin did not constrict the PA and Ao, while marked DA constriction was induced by indomethacin. Methylene blue constricted both the PA and Ao as well as the DA, and the constrictive effects on the PA and Ao were dose-dependent. This is consistent with the finding that the relaxation of pulmonary vascular smooth muscle was more readily achieved via cGMP by guanylate cyclase activation [10].

The slight increase in the Ao caliber is considered to be a compensatory change after DA constriction, because it occurred transiently in the L-NAME-treated group but was sustained in the indomethacin-treated group, and was proportional to the magnitude and the duration of the DA constriction. The slight increase in the DA caliber at $24 \mathrm{hr}$ after methylene blue injection may be a rebound effect after moderate DA constriction, and dilation of the DA may cause a slight secondary increase in the PA caliber. However, the above hypotheses require further studies for confirmation.

We conclude that L-NAME caused slight constriction of the DA, whereas methylene blue and indomethacin caused marked constriction of the vessel, suggesting that the NOcGMP system as well as prostaglandins contribute to the DA patency in fetal rats.

\section{REFERENCES}

1. Abman, S. H., Chatfield, B. A., Hall, S. L. and McMurtry, I. F. 1990. Role of endothelium-derived relaxing factor during transition of pulmonary circulation at birth. Am. J. Physiol. 259: H1921-H1927.

2. Arishima, K., Yamamoto, M., Takizawa, T., Ueda, Y., Kusanagi, M. and Eguchi, Y. 1991. Onset of the constrictive effect of indomethacin on the ductus arteriosus in fetal rats. Acta Anat. 142: 231-235.

3. Arishima, K., Yamamoto, M., Takizawa, T., Somiya, H., Eguchi, Y. and Shiota, K. 1993. Effect of acute maternal alcohol consumption on the fetal ductus arteriosus. Biol. Neonate 63: 40-43.

4. Clyman, R. I., Mauray, F., Roman, C., Rudolph, A. M. and Heymann, M. A. 1980. Circulating prostaglandin $\mathrm{E}_{2}$ concentrations and patent ductus arteriosus in fetal and neonatal lambs. J. Pediatr. 97: 455-461.

5. Clyman, R. I. 1990. Developmental physiology of the ductus arteriosus. pp. 64-75. In: Fetal and Neonatal Cardiology, 1st ed. (Long, W. A. ed.), W. B. Saunders, Philadelphia.

6. Coceani, F. and Olley, P. M. 1973. The response of the 
ductus arteriosus to prostaglandins. Can. J. Physiol. Pharmacol. 51: 220-225.

7. Coceani, F., Kelsey, L. and Seidlitz, E. 1994. Occurrence of endothelium-derived relaxing factor-nitric oxide in the lamb ductus arteriosus. Can. J. Physiol. Pharmacol. 72: 82-88.

8. Coceani, F., Kelsey, L., Seidlitz, E., Marks, G. S., McLaughlin, B. E., Vreman, H. J., Stevenson, D. K., Rabinovitch, M. and Ackerley, C. 1997. Carbon monoxide formation in the ductus arteriosus in the lamb: implications for the regulation of muscle tone. Br. J. Pharmacol. 120: 599-608.

9. Fox, J. J., Ziegler, J. W., Ivy, D. D., Halbower, A. C., Kinsella, J. P. and Abman, S. H. 1996. Role of nitric oxide and cGMP system in regulation of ductus arteriosus tone in ovine fetus. Am. J. Physiol. 271: H2638-H2645.

10. Fullerton, D., Hahn A. R., Banerjee, A. and Harken, A. H. 1994. Pulmonary vascular smooth muscle relaxation by cGMPversus cAMP-mediated mechanisms. J. Surg. Res. 57: 259-263.

11. Kontos, H. A. and Wei, E. P. 1993. Hydroxyl radical dependent inactivation of guanylate cyclase in cerebral arterioles by methylene blue and by LY83538. Stroke 24: 427-434.

12. Levin, D. L., Mills, L. J., Parkey, M., Garriott, J. and Campbell, W. 1979. Constriction of the fetal ductus arteriosus after administration of indomethacin to the pregnant ewe. J. Pediatr. 94: 647-650.

13. Mayer, B., Brunner, F. and Schmidt, K. 1993. Novel actions of methylene blue. Eur. Heart J. 14: 22-26.
14. Momma, K. and Takao, A. 1987. In vivo constriction of the ductus arteriosus by nonsteroidal anti-inflammatory drugs in near-term and preterm fetal rats. Pediatr. Res. 22: 567-572.

15. Moncada, S. 1992. The L-arginine: nitric oxide pathway. Acta Physiol. Scand. 145: 201-227.

16. Morita, T., Perrella, M. A., Lee, M-E. and Kourembanas, S. 1995. Smooth muscle cell-derived carbon monoxide is a regulator of vascular cGMP. Proc. Natl. Acad. Sci. U.S.A. 92: 1475-1479.

17. Murad, F. 1994. Regulation of cytosolic guanylyl cyclase by nitric oxide: the NO-cyclic GMP signal transduction system. Adv. Pharmacol. 26: 19-33.

18. Ribeiro, M. O., Antunes, E., de Nucci, G., Lovisolo, S. M and Zatz, R. 1992. Chronic inhibition of nitric oxide synthesis: A new model of arterial hypertension. Hypertension 20: 298-303.

19. Smith, G. C. S. 1998. The pharmacology of the ductus arteriosus. Pharmacol. Rev. 50: 35-58.

20. Walsh, R. S. and Mentzer, R. M. 1987. Role of cyclic nucleotides in relaxation of fetal lamb ductus arteriosus. Surgery 102: 313-318.

21. Wolin, M. S., Cherry, P. D., Rodenburg, J. M., Messina, E. J. and Kaley, G. 1990. Methylene blue inhibits vasodilation of skeletal muscle arterioles to acetylcholine and nitric oxide via the extracellular generation of superoxide anion. $J$. Pharmacol. Exp. Ther. 254: 872-876. 